\title{
Expression and Distribution of Cyclooxygenase-2 in Human Ovary during Follicular Development
}

Tokuyama Osamu, Nakamura Yoshihiro, Musoh Ayako, Honda Ken-ichi, Ozaki Koji, Ishiko Osamu

\begin{tabular}{|c|l|}
\hline Citation & Osaka City Medical Journal. 49(1); 39-47 \\
\hline Issue Date & 2003-06 \\
\hline Type & Journal Article \\
\hline Textversion & Publisher \\
\hline Right & $\begin{array}{l}\text { C Osaka City Medical Association. } \\
\text { https://osakashi-igakukai.com/. }\end{array}$ \\
\hline
\end{tabular}

Placed on: Osaka City University Repository 


\title{
Expression and Distribution of Cyclooxygenase-2 in Human Ovary during Follicular Development
}

\author{
Osamu Tokuyama, Yoshihiro Nakamura, Ayako Musoh, Ken-ichi Honda, \\ KOJ I OZAKI, and OSAMU I SHIKO
}

Department of Obstetrics and Gynecology, Osaka City University M edical School

\begin{abstract}
Summary
Prostaglandins play important roles for oocyte maturation and follicular rupture. Cyclooxygenase-2 (COX-2), an inducible isoform of a prostaglandin metabolic enzyme, is essential for the timed production of prostaglandins in the ovary. The aim of the present study is to examine expression and distribution of COX-2 in human ovarian follicles at each of the maturation stages. I mmunohistochemical staining shows that COX-2 is expressed in the granulosa cell layer of secondary and developing follicles, but is not detected in primary and Graafian follicles. Western blotting analysis revealed the existence of COX-2 in periovulatory follicular fluid at a mean concentration of $5.6 \pm 0.6 \mathrm{ng} / \mathrm{ml}$. COX-2 might begin to be produced at the secondary follicle stage, and once a follicle reaches the Graafian follicle stage, the production of this enzyme is stopped. After exposure to luteinizing hormone (LH) surge, follicles might resume production of COX-2, and this is secreted into the follicular fluid.
\end{abstract}

Key Words: COX-2; Ovulation; Follicular development; IVF-ET

\section{Introduction}

Follicular development and ovulation is a critical process in mammalian female reproduction, and depends Iargely upon the harmonized effects of pituitary gonadotropins, follicular stimulating hormone (FSH), and luteinizing hormone $(\mathrm{LH})^{11}$. However, how gonadotropins regulate this complex reproductive process is not fully clarified, though some gonadotropin effects are mediated by other mediators. Among these mediators, prostaglandins, the cycl ooxygenase (COX) metabolites of arachidonate, play a crucial role in this process.

During the reproductive period, primordial follicles are irregularly scattered throughout a narrow band in the superficial ovarian cortex. A primordial ovarian follicle consists of a primordial oocyte and a thin monolayer follicle epithelium. As the oocyte increases cellular volume the follicular epithelium becomes cuboidal; this stage is called the primary follicle stage. Progression from the primordial stage to the primary follicle stage is not in an FSH dependent

Received November 15, 2002; accepted November 26, 2002.

Correspondence to: Osamu Tokuyama, MD.

Department of Obstetrics and Gynecology, Osaka City University Medical School,

1-4-3, Asahi-machi, Abeno-ku, Osaka, 545-8585, J apan

Tel: +81-6-6645-3861; Fax: +81-6646-5800

E-mail: otoku@med.osaka-cu.ac.jp 
Tokuyama et al

manner, though the exact mechanism is still unclear. However, once a follicle reaches this stage, it develops in a FSH dependent manner. Under the influence of FSH, the granulosa cell layer becomes thickened, multilayered. This stage is called the secondary follicle stage, and during it a theca cell layer is formed surrounding the granulosa cell layer. The diameter of a follicle reaches about 0.2 to $0.4 \mathrm{~mm}$, and storage of follicular fluid begins to be detected in an antral space. This stage is called the antral follicle stage. After formation of the antral space, the follicle continues to grow to a diameter of $4.0 \mathrm{~mm}$ to $6.0 \mathrm{~mm}$. These size follicles have been recruited in the mid-luteal phase of the previous menstrual cycle and the growth of the recruited follicles is stimulated by the elevated FSH levels in the late luteal to early follicular phases. U sually one follicle that succeeds in gaining a superior estrogen secretion ability is selected from among the cohort and is called the dominant follicle. LH surge, which is induced by the elevation of the serum estrogen concentration, evokes follicular rupture. The ruptured follicle transforms into corpus lutea that produce progesterone to induce secretory change in the uterine endometrium and to sustain implantation. All these processes are largely controlled by gonadotropins, but how these hormones regulate these processes remains unelucidated. It has been reported that some gonadotropin actions are mediated by mediators other than hormonal ones. Prostaglandins (PG), putative intraovarian mediators playing a crucial role in this process, are produced and metabolized by the action of the enzyme, cyclooxygenase ${ }^{2}$. Cyclooxygenase, which converts arachidonic acid into PGs, has two types of isoforms, cydooxygenase -1 (COX-1) and cyclooxygenase 2 (COX-2 $)^{3-5}$. COX-1 is the constitutive form and COX-2 the inducible form ${ }^{6.8}$. The latter is thought to be essential for oocyte maturation and follicular rupture. In rodents or primates, expression and distribution of COX-2 in ovarian follicles has been reported, but there are no reports on human. Our study aims to examine expression and distribution of COX-2 in human ovarian follicles at each maturation stage, and in follicular fluid.

\section{Materials and methods}

\section{Ovarian tissue}

Ovarian tissues were obtained from women receiving gynecological surgery at Osaka City University Hospital, after informed consent was given by all the patients included in this study. Tissues were fixed in $10 \%$ buffered formalin and embedded in paraffin.

\section{Immunohistochemistry}

Sections $(5 \mu \mathrm{m})$ from the paraffin-embedded tissues were deparaffinized with xylene, hydrated with ethanol and water, and then immersed in 3\% hydrogen peroxide for 5 min to block endogenous peroxidase activity. Sections were washed in Phosphate Buffer Saline (PBS) and incubated in PBS containing 10\% normal goat serum blocking solution for 20 min to block nonspecific binding. These were then reacted with anti-human COX-2 rabbit IgG (ImmunoBiological Laboratories Gunma, J apan) 1:200 diluted with blocking solution for $24 \mathrm{~h}$ at $4^{\circ} \mathrm{C}$, and washed 3 times with $0.02 \%$ Tween 20 in PBS. The sections were next reacted with anti-rabbit I gG 1:200 diluted with blocking solution for 1 hour and washed 3 times with $0.02 \%$ Tween 20 in PBS. I mmunocomplexes were colored with $0.2 \mathrm{mg} / \mathrm{ml}$ diaminobenzidine (DAB), $0.1 \%$ hydrogen peroxide in $0.05 \mathrm{M}$ Tris- $\mathrm{HCl}$ buffer. Immunostaining was ascertained by two observers using 
light microscopy.

\section{In vitro fertilization and embryo transfer}

The subjects were 40 patients who underwent in-vitro fertilization and embryo transfer (IVFET) due to tubal factors. Patients with endocrinological abnormalities, which included polycystic ovaries and hyperprolactinemia, or endometriosis or complications of autoimmune diseases, were excluded. Patients were given gonadotropin releasing hormone agonist (Gn-RHa) to suppress pituitary function and received controlled ovarian hyperstimulation. The administration of transnasal nafarelin acetate (Nasanyl, Yamanouchi J apan Tokyo, J apan) was initiated at midluteal phase. After down regulation of gonadotropins was sufficient, ovarian stimulation using human menopausal gonadotropin (hMG) (humegon: Organon J apan, Tokyo, J apan) was initiated on the fifth day of menstruation. Follicle diameter was measured by transvaginal ultrasound, and when the dominant follicle reached at least 16-18 mm in maximum diameter, 10,000 units of human chorionic gonadotropin (hCG) (Mochida J apan, Tokyo, J apan) was administered intramuscularly. After 36 hours from the administration of hCG, follicular puncture and aspiration of follicular fluid was performed under transvaginal ultrasound using a 16-gaugeneedle (COOK, Brisbane, Australia). Pure follicular fluid obtained from the dominant follide was centrifuged immediately at $1,800 \mathrm{rpm}$ for 10 minutes at room temperature. The supernatants were stored at $-80^{\circ} \mathrm{C}$ until assayed.

\section{Immunoaffinity column chromatography with anti human COX-2 rabbit I gG}

Follicular fluid $(0.3 \mathrm{ml})$ stored at $-80^{\circ} \mathrm{C}$ was diluted with $0.7 \mathrm{ml}$ of $10 \mathrm{mM}$ Tris- $\mathrm{HCl}(\mathrm{pH} 7.5)$, passed through a blue HiTrap column $(0.7 \times 2.5 \mathrm{~cm}$, Amersham Pharmacia, Buckinghamshire, England) for exclusion of albumin. The eluate was reacted with HiTrap NHS-activated HP Sepharose (Amersham Pharmacia, Buckinghamshire, England) coupled with anti human COX-2 rabbit IgG, and the adsorbed protein was eluted with $0.1 \mathrm{M}$ glycine- $\mathrm{HCl}$ buffer $(\mathrm{pH} 2.5)$ and dialyzed against $10 \mathrm{mM}$ Tris- $\mathrm{HCl}$ buffer ( $\mathrm{pH}$ 7.6) overnight. The dialyzed protein was freezedried until required for Western blotting analysis.

\section{Western blotting analysis of COX-2 in follicular fluid}

The freeze-dried protein was dissolved with $0.05 \mathrm{ml}$ sodium dodecyl sulfate (SDS) sample buffer, heated at $95^{\circ} \mathrm{C}$ for $3 \mathrm{~min}$ and separated by $10 \%$ SDS polyacrylamide sodium dodecyl sulfate (SDS) gel. The separated proteins in the gel were transferred to polyvinylidene difluoride (PVDF) membrane (Hybond-P, Amersham Pharmacia, Buckinghamshire, England). The blotted membrane was reacted with 1:500 diluted anti-human COX-2 rabbit I gG (ImmunoBiological Laboratories, Gunma, J apan), washed with PBS containing 0.1\% Tween-20, and reacted with anti-rabbit immunogl obulin goat I gG 1:5,000 diluted with PBS containing $20 \%$ fetal bovine serum. The immuno-complexes were detected with an ECL system on Hyperfilm ECL (Amersham Pharmacia).

\section{COX-2 concentrations in follicular fluid}

COX-2 concentrations in follicular fluid were measured using a Human COX-2 Enzyme Immuno Assay KIT (I mmuno-Biological Laboratories). Intra-and inter-assay coefficients of variation (CV) were less than $10 \%$. Data were analyzed for age, number of retrieved oocytes, the total dose of hMG preparation and follicular estradiol, and for progesterone concentration. 
Tokuyama et al

\section{E 2 and P4 concentrations in follicular fluid}

Estradiol (E2) and progesterone (P4) concentrations in follicular fluid were measured utilizing radioimmunoassay (Diagnostic Products Corporation, Los Angeles, USA). Intra- and interassay coefficients of variation were less than $10 \%$.

\section{Statistical analysis}

Data are expressed as mean \pm SD unless otherwise indicated. The correlation were analyzed by simple regression analysis using software package statview.

\section{Results}

\section{I mmunohistochemistry in ovarian tissue}

COX-2 immunostaining was examined in follicles at four stages of follicular maturation. In primary follicles, COX-2 could not be detected in the granulosa cell layer. However, at the secondary follicle stage, COX-2 protein could be detected in the granulosa cell layer. The expression of the COX-2 was uniform throughout the granulosa cell layer. In developing or
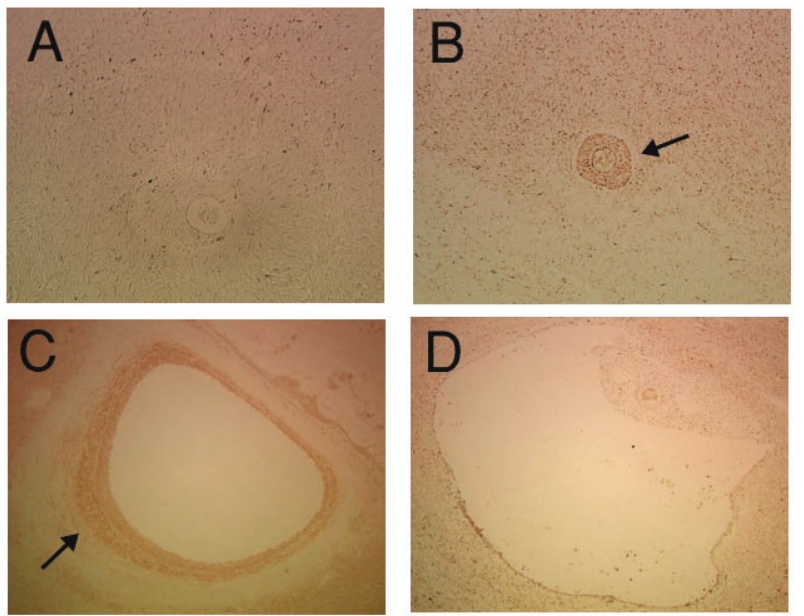

Figure 1. I mmunohistochemistry in ovarian tissue (A: original magnification $\times 400$, B and C: original magnification $\times 200$, D: original magnification $\times 100$ ). No COX-2 expression was found in the primary follicle (A) and the Graafian follicle (D). COX-2 expression was found in the secondary follicle (B) and developing follicle (C) (black arrows).
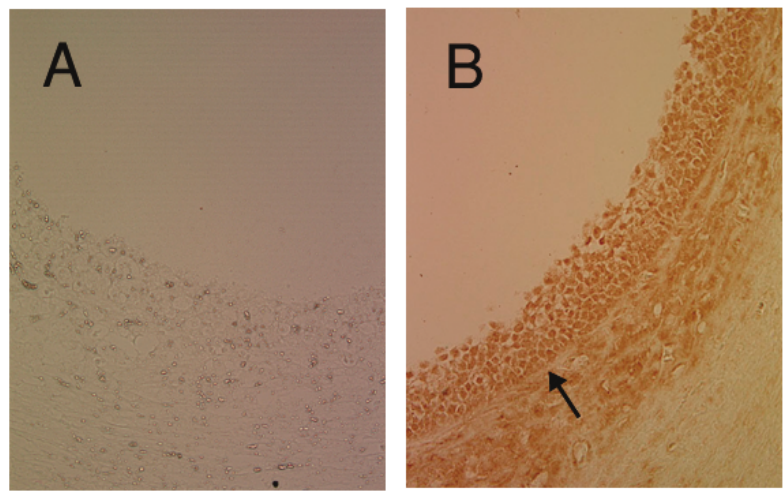

Figure 2. Immunohistochemistry in developing follicle. COX-2 expression in the developing follicle was found with anti-COX-2 IgG (B) but not with IgG blocked with antigen (A) (A and B: original magnification $\times 400$ ). 
antral follicles, COX-2 expression was also recognized, and again the distribution of this enzyme was uniform throughout granulosa cell layer. Sections of Graafian follicles before exposure to LH surge did not show immunoreactivity to COX-2 antibodies (Fig. 1 and 2). A lack of exposure to $\mathrm{LH}$ surge was verified by semiquantitative detection of urinary $\mathrm{LH}$.

\section{Clinical background of patients undergoing IVF-ET}

Table-1 shows the clinical background of patients who underwent IVF-ET. Figures in this table were expressed as mean \pm standard deviation (SD). Mean patient age was $33.5 \pm 0.6$ years. Mean total hMG dose administered was $2058.1 \pm 132.6 \mathrm{IU} / \mathrm{ml}$ and the mean number of oocytes retrieved was $7.8 \pm 1.1$.

Table 1. 40 patients background: age, total hMG, and oocytes retrieved

\begin{tabular}{lcl}
\hline & mean \pm SD & \\
\hline Age (years) & $33.5 \pm 0.6$ & (range: 26.0 to 42.0 ) \\
Total dose of hMG $(I \mathrm{U} / \mathrm{ml})$ & $2058.1 \pm 132.6$ & (range: 600.0 to 5400.0$)$ \\
Oocytes retrieved & $7.8 \pm 1.1$ & (range: 1.0 to 32.0 ) \\
\hline
\end{tabular}

\section{Western blotting and COX-2 concentrations in follicular fluid}

Due to the high concentration of the albumin, exclusion of the albumin through Sepharose column and dialysis is an indispensable step to immunodetection of COX-2 in follicular fluid. The COX-2 protein in follicular fluid sample from an IVF-ET patient showed about 70,000 molecular mass units (Fig. 3). The mean COX-2 concentration in follicular fluid was $5.6 \pm 0.6$ $\mathrm{ng} / \mathrm{ml}$ (range: $0.6-19.5 \mathrm{ng} / \mathrm{ml}$ ). Significant correlations were not found for COX-2 and age, oocytes retrieved, total hMG.

\section{Endocrinological background of patients}

The mean E 2 and P4 concentrations in follicular fluid from 16 patients were $179250.0 \pm$

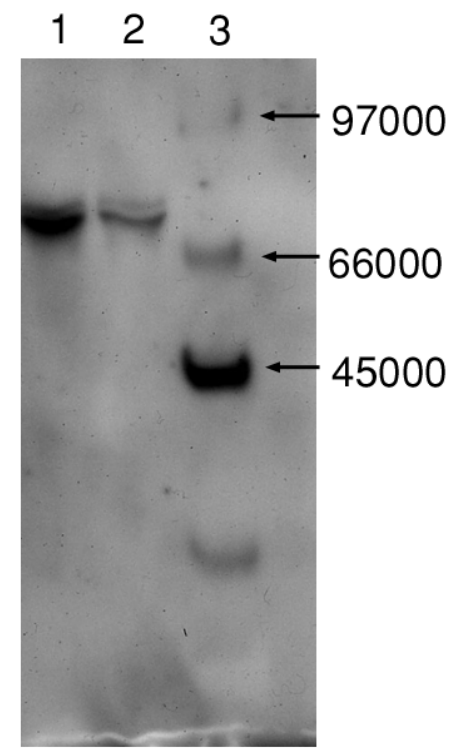

Figure 3. Western blot analysis of protein from follicular fluid shows existence of COX-2. The molecular masses of standard proteins separated on the same gel are indicated on the right side (lane 3). The band showing existence of COX-2 corresponds to a molecular weight of about 70,000 (lane 1 and 2). 
Tokuyama et al

$118953.0 \mathrm{pg} / \mathrm{ml}$ and $6639.0 \pm 3194.0 \mathrm{ng} / \mathrm{ml}$, respectively (Table 2). Correlation was found between COX-2 and E 2 concentration in follicular fluid $(R=0.538, p<0.05)$, but not between COX2 and P4 (Fig. 4).

Table 2. COX-2, E2 and P4 concentrations in follicular fluid of 16 patients

\begin{tabular}{|c|c|c|}
\hline & mean $\pm \mathrm{SD}$ & \\
\hline COX-2 (ng/ml) & $3.6 \pm 1.5$ & (range: 0.6 to 6.5 ) \\
\hline $\mathrm{E} 2(\mathrm{pg} / \mathrm{ml})$ & $179250.0 \pm 118953.0$ & (range: 44500.0 to 493000.0 ) \\
\hline $\mathrm{P} 4$ (ng/ml) & $6639.0 \pm 3194.0$ & (range: 2640.0 to 14000.0 ) \\
\hline
\end{tabular}
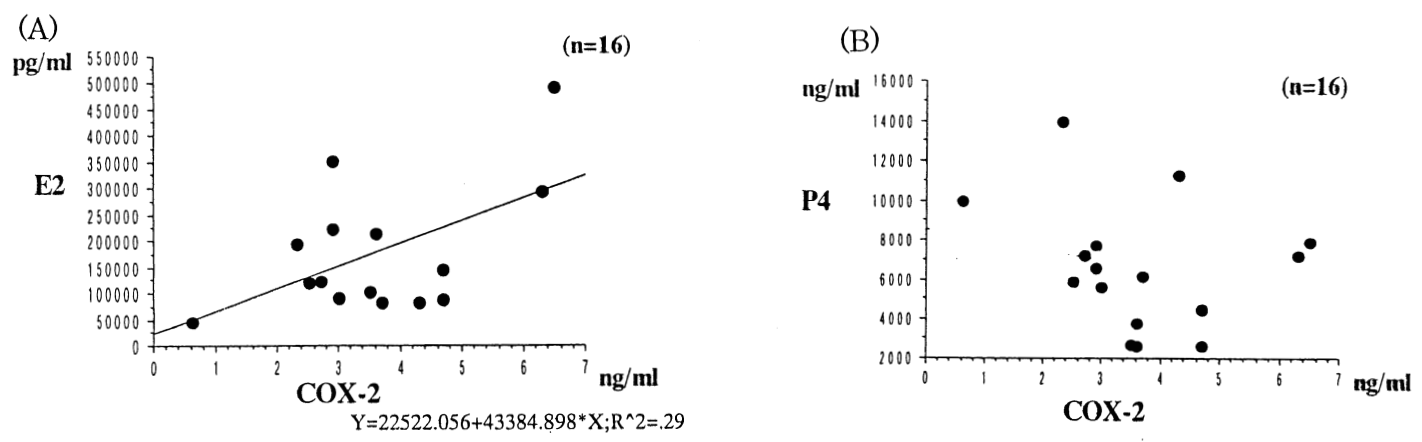

Figure 4. Correlation between $C O X-2$ and $E 2$ concentrations in follicular fluid. There was correlation between COX-2 and E2 ( $R=0.538, p<0.05)(A)$, but not between COX-2 and $P 4(B)$.

\section{Discussion}

In this study, we demonstrated that COX-2 protein begins to be expressed at the secondary follicle stage in human ovary and that this expression is withdrawn just before exposure to LH surge. We also measured COX-2 concentrations in follicular fluid after administration of hCG, which can substitute for the LH surge function in patients who have received Gn-RHa desensitization against the pituitary gland. We also verified the presence of COX-2 in follicular fluid after exposure to hCG in IVF-ET patients.

Oocyte maturation and follicular rupture largely depend on coordinated secretion of pituitary gonadotropins and many mediators are involved in follicular maturation and rupture, with prostanoids considered to play a crucial role. Previous studies demonstrated that COX-2, but not COX-1, is a major source of PGs in primate and other mammalian species". Among these COX-2 metabolites, PGE 2 and F $2 \alpha$ are especially considered to play pivotal roles in follicular development and rupture ${ }^{10}$.

Early experiments on rodents showed that PGE 2 was involved in activation of the cumulus oocyte complex ${ }^{11}$, which is characterized by polarization and expansion of the granulosa cells surrounding the oocyte with production of hyaluronic acid-enriched proteoglycans ${ }^{12}$. This process is considered to be critical for successful fertilization and follicular rupture. Oocytes obtained from COX-2 deficient mice showed a severely compromised fertilization rate ${ }^{13)}$, and EP2, a PGE2 receptorsubtype, deficient mice also showed a much reduced fertilization rate ${ }^{14}$. Davis et al reported that PGE 2 supplementation can restore cumulus activation in COX-2 deficient mice ${ }^{15}$. In bovine, Calder et al reported that COX-2 and PGE 2 play very essential roles in the cumulus oocyte complex ${ }^{16)}$. These lines of reporting suggest that COX-2 derived PGE 2 is 
required for oocyte cumulus complex maturation in ovarian follicles. In our study, COX-2 began to be detected at the secondary follicle stage and continued to be detected in granulosa cell layers of antral follicles. This finding suggests that COX-2 and the metabolites of this enzyme might be involved in follicular development including oocyte cumulus complex maturation in human.

COX-2 and its metabolites are also essential in follicular rupture, which is induced by LH surge and has a process similar to an inflammatory reaction Recent reports demonstrated that prostaglandins, especially PGE 2 and PGF $2 \alpha$, play critical roles in the events of follicular rupture and that COX-2 is a essential enzyme to produce these metabolites. Administration of nonselective COX inhibitors to monkeys has been shown to have an adverse effect on follicular rupture, and this inhibitory effect is reversed by the administration of PGF $2 \alpha^{17}$. Recently, the same effect of COX inhibitors was reported in human ${ }^{18}$. COX-2 knockout mice have a defect in follicular rupture, which can be restored by the exogenous administration of PGE $2^{15}$. Sirois demonstrated that COX-2 expression by granulosa cells and prostaglandin concentrations in follicular fluid of preovulatory follides rose dramatically in response to the ovulatory gonadotrophin surge ${ }^{19}$. The interval between the onset of the ovulatory gonadotrophin surge and follicular rupture varies in mammalian species. Sirois and Dore proposed that elevated COX-2 activity and the resulting increase in follicular fluid PG determine the timing of ovulation in mammals ${ }^{20}$. In our study, preovulatory follides before the LH surge did not show any signals in immunohistochemical study, and the same observation was reported in preovulatory rhesus monkey follicles before LH surge ${ }^{21}$. We speculated that temporal withdrawal of COX-2 in the granulosa cells layer of Graafian follides before exposure to LH surge is partially explained by the follicles' readiness to respond to LH surge and the subsequent ovulatory events in which COX-2 and its metabolites play pivotal roles. However, further intensive study is required to elucidate this temporal withdrawal of the enzyme.

We previously reported follicular COX-2 concentrations in 20 women ${ }^{22)}$; and this time we expand the subject base to 40 patients. All patients included in this study received pituitary suppression by Gn-RHa, and superovulatory treatment using hMG. LH surge which induces COX-2 in follicles and induces resumption of the meiosis oocyte is substituted by hCG. However, the COX-2 concentrations in this study might not reflect COX-2 concentrations in natural ovulatory follicles, as previous studies demonstrated COX-2 induction in the granulosa cell layer in preovulatory follicles after the exposure to LH surge. COX-2 in follicular fluid is considered to be secreted from granulosa cells after HCG stimulation. COX-2 concentrations and E 2 showed a positive relationship in our study, and this finding suggested that the COX-2 concentration in follicular fluid could be a candidate as a novel indicator for the function of granulosa cells. We could not determine any relationship between COX-2 concentration and P4 levels in follicular fluid.

We obtained follicular fluid 36 hours after hCG administration; around this period, P4 secretion is considered to be unstable. COX-2 and its metabolites are also very important bioactive substances in the formation of corpus lutea, though further study is required to clarify the mechanism of how COX-2 and prostaglandins regulate this process.

We have demonstrated that COX-2 might not be produced at the primary follicle stage, but begins to be produced at the secondary follicle stage in human ovary and continues to be expressed in the granulosa cell layers of developing follicles until follicles reach the Graafian 
Tokuyama et al

follicle stage. J ust before the exposure to LH surge, COX-2 expression is temporarily withdrawn. We also showed that the existence of this enzyme in human follicular fluid after administration of hCG in IVF-ET patients. These findings collectively suggest that COX-2 is essential in follicular development and rupture in human ovary.

\section{Ackowledgement}

We thank the gynecologists at Osaka city medical School for their great support. This Work was supported by the Osaka Medical Research Foundation for Incurable Diseases.

\section{References}

1. Espey L L: Current status of the hypothesis that mammalian ovulation is comparable to an inflammatory reaction. Biol Reprod 50: 233-238 (1994)

2. Smith W L, DeWitt D L: Prostaglandin endoperixide H synthase-1 and -2. Adv Immunol 62: 167-215 (1996)

3. Smith W L, Marnett L J : Prostaglandin endoperoxide synthase: structure and catalysis. Biochim Biophys Acta 24: 1-17 (1991)

4. Needleman P, Turk J , J akschik B A, Morrison A R, Lefkowith J B: Arachidonic acid metabolism. Annu Rev Biochem 55: 69-102 (1986)

5. Silva P J , J uengel J L, Rollyson M K, Niswender G D: Prostaglandin metabolism in the ovine corpus luteum: catabolism of prostaglandin F $2 \alpha$ (PGF $2 \alpha$ ) coincides with resistance of the corpus luteum to PGF $2 \alpha$. Biol Reprod 63: 1229-1236 (2000)

6. Majima M, I sono M, Ikeda Y, Hayashi I, Hatanaka K, Harada Y, Katsumata O, Yamashina S, Katori M, Yamamoto S: Significant roles of inducible cyclooxygenase (COX)-2 in angiogenesis in rat sponge implants. J pn J Pharmacol 75: 105-114 (1997)

7. Tsujii M, Kawano S, Tsuji S, Sawaoka H, Hori M, DuBois R N: Cyclooxygenase regulates angiogenesis induced by colon cancer cells. Cell 93: 705-716 (1998)

8. Katori M, Majima M: Cyclooxygenase-2: its rich diversity of roles and possible application of its selective inhibitors. Inflamm Res 49: 367-392 (2000)

9. Wong W Y L, Richards J S: Evidence for two antigenically distinct molecular weight variants of prostaglandin H synthase in the rat ovary. Mol Endocrinol 5: 1269-1279 (1991)

10. Liu J , Sirois J : Follicle size-dependent induction of prostaglandin G/H synthase-2 during superovulation in cattle. Biol Reprod 58: 1527-1532 (1998)

11. Eppig J J : Prostaglandin E2 stimulates cumulus expansion and hyaluronic acid synthesis by cumuli oophori isolated from moce. Biol Reprod 25: 191-195 (1981)

12. Eppig J J : FSH stimulates hyaluronic acid synthesis by oocyte-cumulus cell complexes from mouse preovulatory follicles. Nature 281: 483-484 (1979)

13. Lim H, Paria B C, Das S K, Dinchuk J E, Langenbach R, Trzaskos J M, Dey S K: Multiple female reproductive failures in cyclooxygenase-2 deficient mice. Cell 17: 197-208 (1997)

14. Hizaki H, Segi E, Sugimoto Y, Hirose M, Saji T, Ushikubi F, Matsuoka T, Noda Y, Tanaka T, Yoshida N, Narumiya S, Ichikawa A: Abortive expansion of the cumulus and impaired fertility in mice lacking the prostaglandin E receptor subtype EP2. Proc Natl Acad Sci USA 96: 10501-10506 (1999)

15. Davis B J , Lennard D E, Lee C A, Tiano H F, Morham S G, Wetsel W C, Langenbach R: Anovulation in cyclooxygenase-2 deficient mice is restored by prostaglandin E2 and interleukin-1b. Endocrinology 140: 2685-2695 (1999)

16. Calder M D, Caveney A N, Westhusin M E, Watson A J : Cyclooxygenase-2 and prostaglandin E2 (PGE2) receptor messenger RNAs are affected by bovine oocyte maturation time and cumulus-oocyte complex quality and PGE2 induces moderate expansion of the bovine cumulus invitro. Biol Reprod 65: 135-140 (2001)

17. Wallach E E, Bronson R, Hamada Y, Wright $\mathrm{K} \mathrm{H}$, Stevens $\mathrm{V}$ C: Effectiveness of prostaglandin F $2 \alpha$ in restoration of hMG-hCG induced ovulation in indomethacin-treated rhesus monkeys. Prostaglandins 10: 129-138 (1975)

18. Mendonca L L, Khamashta M A, Nelson-Piercy C, Hunt B J , Hughes G R: Non-steroidal anti-inflammatory drugs as a possible cause for reversible infertility. Rheumatology 39: 880-882 (2000)

19. Sirois J : Induction of prostaglandin endoperoxide synthase-2 by human chorionic gonadotropin in bovine 
COX-2 Expression during Follicular Development

preovulatory follicles in vivo. Endocrinology 135: 841-848 (1994)

20. Sirois J, Dore M: The late induction of prostaglandin G/H synthase-2 in equine preovulatory follicles supports its role as a determinant of the ovulatory process. Endocrinology 138: 4427-4434 (1997)

21. Duffy D M, Stouffer R L: The ovulatory gonadotrophin surge stimulates cyclooxygenase expression and prostaglandin production by the monkey follicle. Mol Hum Reprod 7: 731-739 (2001)

22. Tokuyama O, Nakamura Y, Musoh A, Honda K, Ishiko O and Ogita S: Expression and distribution of cyclooxygenase-2 in human periovulatory ovary. Int J Mol Med 8: 603-606 (2001) 